\title{
TU/e EmonOWEN

\section{Design rules for out-of-plane stability of roller bent steel arches with FEM}

\section{Citation for published version (APA):}

Spoorenberg, R. C., Snijder, H. H., Hoenderkamp, J. C. D., \& Beg, D. (2012). Design rules for out-of-plane stability of roller bent steel arches with FEM. Journal of Constructional Steel Research, 79, 9-21. https://doi.org/10.1016/j.jcsr.2012.07.027, https://doi.org/10.1016/j.jcsr2012.07.027

\section{DOI:}

10.1016/j.jcsr.2012.07.027

10.1016/j.jcsr2012.07.027

\section{Document status and date:}

Published: 01/01/2012

\section{Document Version:}

Accepted manuscript including changes made at the peer-review stage

\section{Please check the document version of this publication:}

- A submitted manuscript is the version of the article upon submission and before peer-review. There can be important differences between the submitted version and the official published version of record. People interested in the research are advised to contact the author for the final version of the publication, or visit the $\mathrm{DOI}$ to the publisher's website.

- The final author version and the galley proof are versions of the publication after peer review.

- The final published version features the final layout of the paper including the volume, issue and page numbers.

Link to publication

\section{General rights}

Copyright and moral rights for the publications made accessible in the public portal are retained by the authors and/or other copyright owners and it is a condition of accessing publications that users recognise and abide by the legal requirements associated with these rights.

- Users may download and print one copy of any publication from the public portal for the purpose of private study or research.

- You may not further distribute the material or use it for any profit-making activity or commercial gain

- You may freely distribute the URL identifying the publication in the public portal.

If the publication is distributed under the terms of Article 25fa of the Dutch Copyright Act, indicated by the "Taverne" license above, please follow below link for the End User Agreement:

www.tue.nl/taverne

Take down policy

If you believe that this document breaches copyright please contact us at:

openaccess@tue.nl

providing details and we will investigate your claim. 


\title{
Design rules for out-of-plane stability of roller bent steel arches with FEM
}

\author{
R.C. Spoorenberg a,*, H.H. Snijder a J.C.D. Hoenderkamp ${ }^{\text {a }}$, D. Beg ${ }^{b}$ \\ a Eindhoven University of Technology, Faculty of Built Environment, P.O. Box 513, 5600 MB Eindhoven, The Netherlands \\ b University of Ljubljana, Faculty of Civil and Geodetic Engineering, Jamova 2, 1000 Ljubljana, Slovenia
}

\section{A R T I C L E I N F O}

\section{Article history:}

Received 14 May 2012

Accepted 25 July 2012

Available online $\mathrm{xxxx}$

\section{Keywords:}

Roller bent arch

Out-of-plane buckling

Finite element modeling

Design rules

\begin{abstract}
A B S T R A C T
This paper describes a numerical investigation into the out-of-plane buckling behavior of freestanding roller bent steel arches. As roller bent arches have structural imperfections which differ considerably from those of hot-rolled or welded sections, specific attention is paid to their inclusion in the numerical model. Sensitivity analyses are performed to assess the influence of the imperfections due to roller bending on the out-of-plane buckling response. The accuracy of the finite element model is checked by comparing the results with earlier performed experiments as presented in a related paper. The finite element model is able to replicate the structural behavior displayed by the experiments with good accuracy. A database is created with elasticplastic buckling loads for a large number of freestanding roller bent arches. The numerical data is analyzed and presented in a so-called imperfection parameter diagram from which imperfection parameter curves are derived. The imperfection parameter curves are substituted into the European column curve formulation, leaving the original column curve formulation unaffected but extending its applicability to the out-of-plane buckling response of roller bent arches. The column curve with proposed imperfection parameter expressions can be used to check the out-of-plane buckling response of a roller bent steel arch with known non-dimensional slenderness.
\end{abstract}

(c) 2012 Elsevier Ltd. All rights reserved.

\section{Introduction}

The application of roller bent steel has seen a steady increase in the construction industry over the past decades. Ease of manufacturing make roller bending a suitable method for achieving curved structures. Roller bent steel is often applied in circular arch structures where its primary function lies in carrying the acting loads to the abutments. The loads are resisted by means of a combination of compression and bending, making the member susceptible to buckling. When local buckling is not considered, arch instability can be subdivided into three different categories: snap-through buckling (Fig. 1(a)), in-plane buckling (Fig. 1(b)) and out-of-plane buckling (Fig. 1(c)). The latter occurs when an arch has no lateral bracing and is considered 'freestanding'. This paper presents a study of the structural performance of freestanding circular roller bent steel arches by means of the finite element method, for which out-ofplane buckling is the governing failure mode. The performance of the finite element model is verified through comparison with experimental results as reported in a related paper, La Poutré et al. [1].

\footnotetext{
* Corresponding author at: Eindhoven University of Technology, Faculty of Built Environment, Den Dolech 2, P.O. Box 513, 5600 MB Eindhoven, The Netherlands. Tel.: + 3140247 2948; fax: + 31402450328 .

E-mail address: r.c.spoorenberg@bwk.tue.nl (R.C. Spoorenberg).
}

\subsection{Previous studies on out-of-plane arch buckling}

The earliest theoretical studies on out-of-plane arch buckling only considered elastic buckling where material non-linearities and imperfections were ignored. Valuable contributions were published by Timoshenko and Gere [2] and Vlasov [3] who provided formulae to approximate the elastic out-of-plane buckling load of freestanding arches. Further refinements to calculation procedures for approximating the elastic buckling load were proposed by Vacharajittiphan and Trahair [4], Yoo [5] and Rajasekaran and Padmanabhan [6].

The necessity to include material non-linearities and imperfections to obtain an accurate representation of out-of-plane buckling behavior of arches was recognized in Japan by the end of the 1970s. Research studies included experiments conducted on arches with square hollow sections by Sakimoto et al. [7] and welded I-sections by Sakata and Sakimoto [8] supplemented with finite element analyses by Komatsu and Sakimoto [9], Sakimoto and Komatsu [10] and Sakimoto and Komatsu [11]. These Japanese research studies culminated in design rules. For the calculation of the slenderness, the arch was treated as a straight column under uniform compression with identical cross-section, where the arch length corresponded with the column length. Column curves were proposed by Sakimoto et al. [12] and Sakimoto and Sakata [13] to allow a check of the out-of-plane arch stability. Their applicability was limited to arches with square hollow sections and rise-to-span ratios between 0.1 and 0.2 .

As the Japanese design provisions treated the out-of-plane arch buckling case identically to that of a column, the rise-to-span ratio 
(a) Snap-through

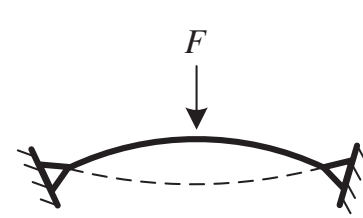

(b) In-plane buckling

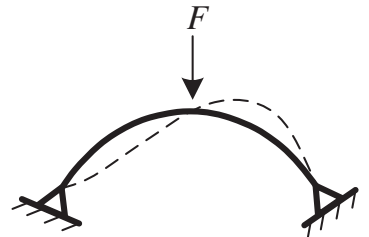

(c) Out-of-plane buckling

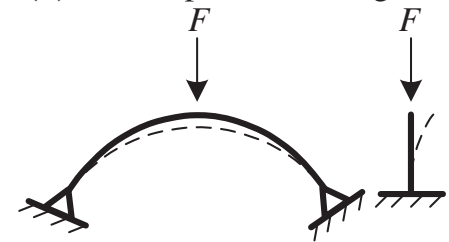

Fig. 1. Global instability phenomena for arches.

of the arch was considered to be of minor importance. However, earlier theoretical studies revealed that the rise-to-span ratio can have a significant effect on arch buckling. This was recognized by Papangelis and Trahair [14] who performed experiments on arch buckling. These experiments were used to validate an in-house finite element code developed by Pi and Trahair [15] from which design rules for arch buckling were developed and proposed. Pi and Trahair [16] stated that for pin-supported arches subjected to radial loading and simply-supported arches subjected to uniform bending, the Australian column curves were considered suitable for the design of arches failing by out-of-plane buckling. For out-of-plane fixed arches a similar approach was used; Pi and Bradford [17]. According to Pi and Trahair [16] and Pi and Bradford [17] the arch slenderness was defined as the square root of the ratio between the plastic capacity and out-of-plane elastic buckling load, taking implicitly into account the geometric properties of the arch. For arches subjected to vertical loading, interaction formulae were proposed to check the out-ofplane stability. These interaction formulae are analogous to those of a beam-column failing by elastic-plastic buckling. The interaction formulae were valid for out-of-plane simply supported arches, Pi and Trahair [18] and out-of-plane fixed arches, Pi and Bradford [17].

\subsection{Scope and aims}

It is clear that the out-of-plane buckling behavior of steel arches has received large attention, comprising analytical, numerical and experimental studies. However, investigations involving material non-linearities and imperfections were limited to either welded box-sections or wide-flange sections for which the influence of the roller bending process on the structural properties of the arch was not taken into account. Earlier experiments and finite element analyses by the authors have shown the influence of the roller bending process on the structural properties of wide flange sections. Using the existing design rules to check the out-of-plane buckling response of freestanding arches without taking into account the influence of the roller bending process can lead to either conservative or unconservative designs. The main goal of this paper is two-fold: providing numerical modeling techniques for roller bent steel members and suggesting design rules for out-of-plane buckling of arches with finite element analyses. The European column curve formulation as described in EN 1993-1-1 [19] (Eurocode3) will be adapted to include the out-of-plane buckling of arches. The results from 3 different finite element analysis types will be used to express the numerical data in the column curve diagram to arrive at a design rule. Arches can be subjected to a wide range of loading types. In general a distinction is made between symmetric and unsymmetric loads. The present finite element study is limited to the former one. Design rules are proposed for a total of four load cases as shown in Fig. 2. The arch geometry is shown in Fig. 2(a), where $S$ is the arch length, $R$ the radius, $2 \gamma$ is the subtended angle, $L$ is the span and $f$ is the rise. Arches with two opposite end moments (Fig. 2(a)) and a radially distributed load (Fig. 2(b)) are rather academic load cases. These load cases serve for comparison with other load cases, as the internal forces are limited to uniform bending or uniform compression for an arch under two opposite end moments or a radially distributed load, respectively. Arches with a central point load (Fig. 2(c)) or uniformly distributed load (Fig. 2(d)) display a combination of internal bending moments and compressive forces. During the loading phase, the loads will undergo no directional change and are hence termed gravity loading. The present study is limited to circular I-section arches made from either steel grade S235 or steel grade S355 bent about their major axis through the roller bending process.

With the exception of arches subject to two opposite end moments, all arches are pin-supported, preventing outward spreading (a) Two opposite end moments - Uniform bending

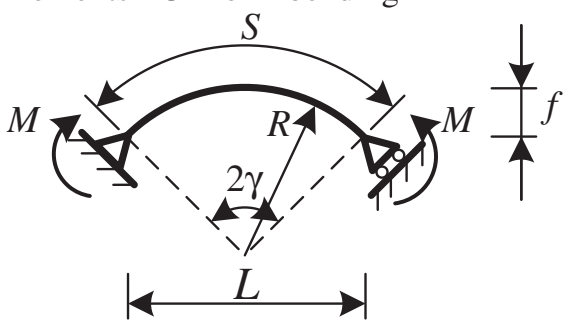

(c) Central point load

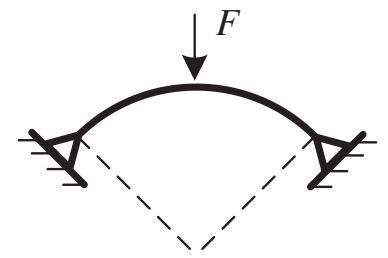

(b) Radially distributed load - Uniform compression

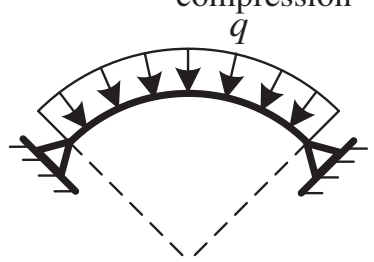

(d) Uniformly distributed load

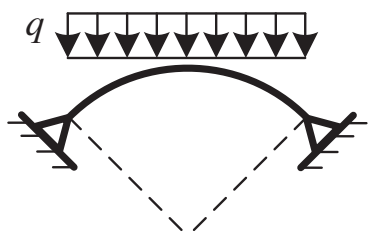

Fig. 2. Load cases under investigation. 
of the support and introducing compressive action in the arch-rib. Arches under uniform bending need to be simply supported, as pin-ended support conditions would induce a small normal force. No in-plane fixed boundary conditions are considered. For all arches the torsional degree of freedom is fixed at the support (fork support). From preliminary finite element analyses it was found that arches with out-of-plane pin-ended conditions provided little resistance to out-of-plane buckling. In order to compensate for this and hence consider arches which can sustain sufficient loads before failing by out-of-plane buckling all arches are fixed out-of-plane at the supports and warping deformations are prevented (restrained warping). The behavior of the supports with respect to the local coordinate system of the arch is outlined in Section 2.3.

\section{Finite element modeling}

The general purpose finite element package ANSYS v.11.0 is used to perform the numerical computations. All analyses are performed in the implicit environment.

\subsection{Types of analysis}

For each arch configuration three types of analysis are necessary to obtain the buckling response and to plot the finite element results in the column curve diagram: Linear Buckling Analysis (LBA), Material Non-linear Analysis (MNA) and Geometrical Material Non-linear Imperfect Analysis (GMNIA). An additional Geometrical Non-linear Imperfect Analysis (GNIA) was performed to obtain the load corresponding to the onset of yielding. It should be noted that a LBA produces a simplified representation of buckling behavior of arches, while GNIA and GMNIA are able to account for more complex buckling behavior of arches. The loads will be represented by the so-called load amplifiers $\alpha$. The load amplifier is the load divided by the applied loading, resulting in a load parameter independent of the type of loading (point load, uniformly distributed load or end moments). For example, for a GMNIA the ultimate load amplifier for an arch subject to a central point load can be obtained as follows:

$\alpha_{u l t}=F_{u l t} / F$.

Where:

$\alpha_{\text {ult }} \quad$ is the ultimate load amplifier obtained by GMNIA;

$F_{\text {ult }} \quad$ is the maximum central point load obtained from the load-deflection characteristics;

$F \quad$ is the central point load applied on the arch.

As $F \quad$ is always equal to unity, $F_{\mathrm{ult}}$ is equal to $\alpha_{\mathrm{ult}}$. Analogous to $\alpha_{\mathrm{ult}}$, $\alpha_{\mathrm{cr}}$ and $\alpha_{\mathrm{pl}}$ can be computed from $F_{\mathrm{cr}}$ and $F_{\mathrm{pl}}$, respectively.

\subsection{Model}

The arch is meshed with shell elements. The selected SHELL181 element is a four-node shell element which permits inclusion of residual stresses and is capable of handling large rotations and large strains. A reduced integration scheme has been adopted, featuring a single integration point over the surface and 5 integration points over the shell thickness to capture growth of plastic zones.

\subsection{Boundary conditions and loading}

The boundary conditions and loading types comply with those described in Section 1.2. Fig. 3 shows the finite element model for a pin-supported arch. Finite element models comprising shell elements need specific attention with respect to their supports or boundary conditions, i.e. enforcing zero displacements and/or zero rotations.
In the present finite element model Multi-Point-Constraint elements (MPC184 in ANSYS) were used to ensure a smooth introduction of the support reactions. The supports were applied at the mid-height node of the web. The MPC elements applied over the cross-section ensured proper transfer of the displacements and rotations of the mid-height node to the adjacent nodes. Restrained warping at the support is included when applying MPCs over the web and flanges, thereby preventing separate rotation of the flanges (Fig. 4).

The number of MPC elements is related to the shell element distribution over the height of the web and width of the flanges. Loads are applied at the centroid of the cross-section. The element mesh shown in Fig. 3 and Fig. 4 is based on mesh refinement studies as presented in Section 2.8 .

\subsection{Imperfections}

\subsubsection{Residual stresses}

The residual stress model proposed by Spoorenberg et al. [20] is used to define the initial stress state in the roller bent steel member prior to loading (Fig. 5(a)). The compressive residual stresses and tensile residual stresses are denoted negative and positive respectively. As this residual stress model is presented in non-dimensional form, the nominal yield stress according to material specifications is used to obtain stress values $\left(f_{\mathrm{y}}=235 \mathrm{~N} / \mathrm{mm}^{2}\right.$ for $\mathrm{S} 235$ and $f_{\mathrm{y}}=355 \mathrm{~N} / \mathrm{mm}^{2}$ for S355). The residual stress values are applied at the integration points of the shell element which coincide with the element centroid. As the residual stress value in the integration point defines the stress state for the whole element, a step-wise pattern is obtained for the finite element model (Fig. 5(b)).

\subsubsection{Geometric imperfections}

La Poutré [21] measured the out-of-straightness of 12 full-scale roller bent arches prior to testing. Lateral crookedness, radial crookedness and twist imperfections were measured on HE 100A arches with an arch length $S$ of $6 \mathrm{~m}$ (Fig. 6). A 'substitute' out-of-straightness pattern was derived that represents the measured geometric deviations in the arch with nearly identical out-of-plane elastic-plastic buckling behavior. The substitute out-of-straightness is characterized by the lowest global eigenmode from a LBA and variable amplitude. The lowest eigenmode was selected as it is regarded as the most detrimental shape to define the out-of-straightness because it shows strong coherence with the arch deflections at elastic-plastic buckling.

In a finite element parametric study the amplitude is modified to achieve a best fit to the measured out-of-straightness for each of the 12 arches. This produced a total of 12 different amplitudes Spoorenberg [22]. From this finite element study it was concluded that the lowest global eigenmode from a LBA with amplitude of $S / 1000$ provides a good substitute to define the out-of-straightness of a roller bent arch. It is mentioned that the above suggested 'substitute' out-ofstraightness is only applicable to freestanding arches subject to out-of-plane buckling failure.

\subsubsection{Material modeling}

During roller bending the stress-strain curve of the material prior to forming changes from a single bi-linear curve to several different non-linear curves over the cross-section. From the experimental observations a prediction model was developed that defines generally applicable material models for a roller bent wide flange section; Spoorenberg et al. [23]. The prediction model consists of two different components: the estimation of salient mechanical properties of roller bent steel and the development of curves defining the stress-strain characteristic. Depending on the steel grade (S235 or S355), bending ratio $(R / h)$ (ratio between arch radius $R$ and nominal section height $h$ ) and yield stress of the material prior to forming $\left(f_{\mathrm{y} ; \mathrm{s}}\right)$, the prediction model produces the 7 different stress-strain curves for 9 zones of the roller bent arch (Fig. 7). 


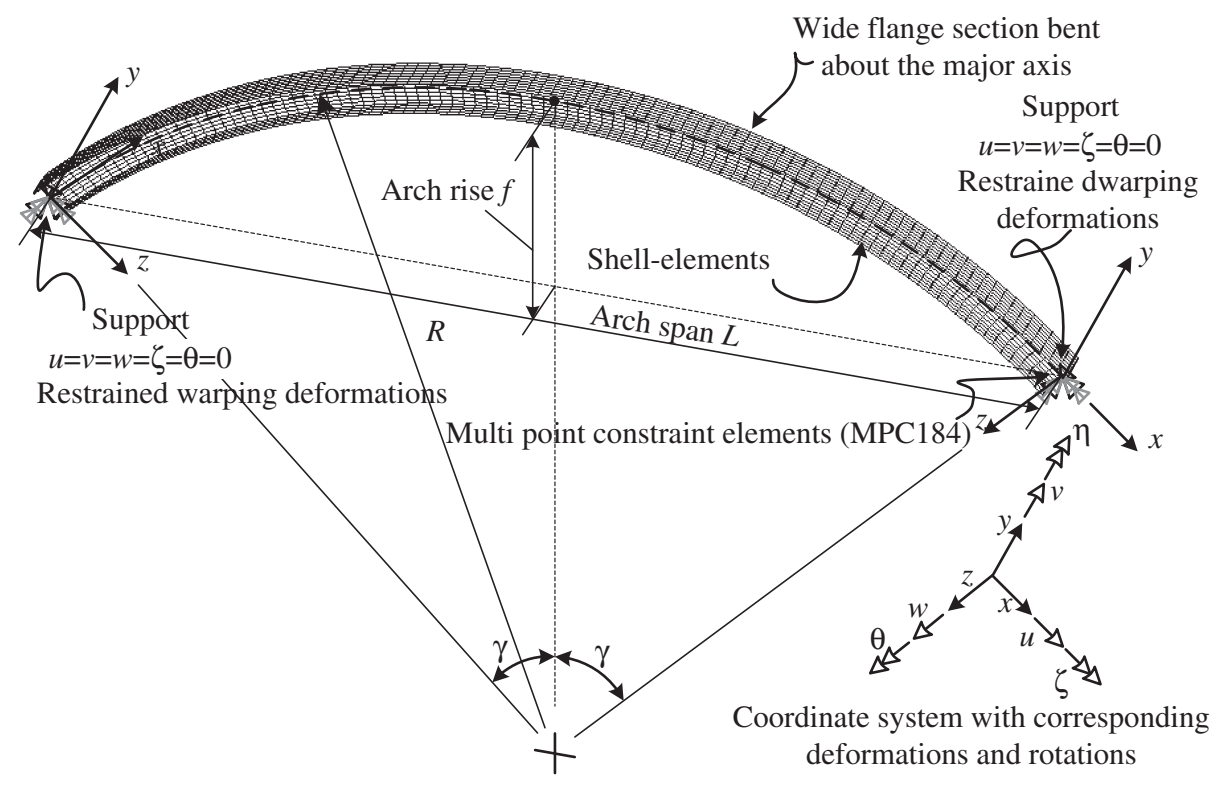

Fig. 3. Finite element model with local coordinate system.

From tensile tests conducted on coupons taken from roller bent arches it was observed that the flanges exhibit gradual yielding behavior. Therefore, the modified Ramberg-Osgood model, which is used for stainless steel and aluminum members, was selected to define the stress-strain curve from the onset of loading up to the ultimate tensile stress in the flanges. A bi-linear material curve was selected to approximate the material characteristics in the web. The roller bent stress-strain curves are employed for both compression and tension, i.e. the tensile and compression regime have an identical stress-strain curve. For the GMNIA the stress-strain curves from this prediction model were converted to true-stress, true-strain curves to account for large strain effects. The material models were entered in the finite element model by discrete stress-strain values, resulting in a piece-wise curve for each of the 7 zones (Fig. 8).

The materials' response to plastic straining is described by the Von Mises yield criterion, Prandtl-Reuss flow rule and an isotropic hardening law. The difference between the nominal yield stress according to material specifications and the measured yield stress in roller bent steel is caused by two different phenomena. Firstly, the material is plastically strained during roller bending resulting in hardening effects thereby changing the yield stress values. Secondly, prior to roller bending, there exists already a difference between the nominal yield stress $\left(f_{\mathrm{y}}\right)$ and the measured yield stress $\left(f_{\mathrm{y} ; \mathrm{s}}\right)$, where measured values usually exceed nominal ones. Differences between $f_{\mathrm{y}}$ and $f_{\mathrm{y} ; \mathrm{s}}$ were significant for steel grade S235 whereas for steel grade S355 this difference less pronounced. Including the difference between $f_{\mathrm{y}}$ and $f_{\mathrm{y} ; \mathrm{s}}$ in the calibration process of the prediction model would

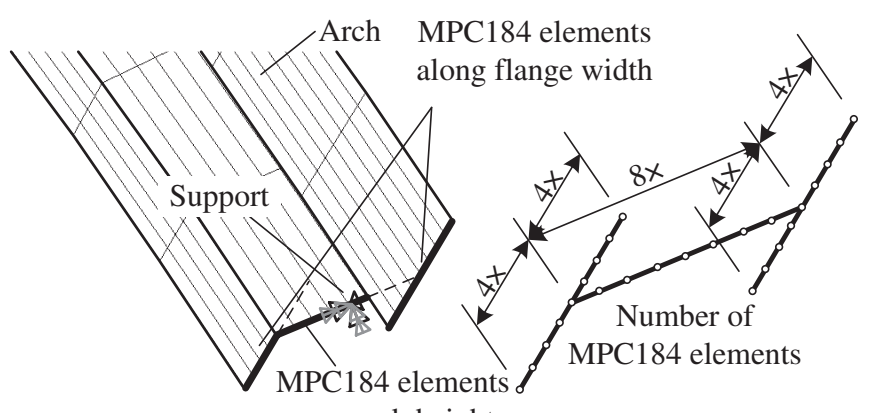
over web height

Fig. 4. Modeling of restraints. imply that the difference between nominal yield stress and measured yield stress in roller bent steel is completely due to the roller bending process. This, of course, is not correct. Therefore, the prediction model was calibrated on the difference between yield stress values obtained from measurements of coupons taken from straight sections, serving as reference sections, and coupons taken from roller bent sections. Although calibration in this way gives a better representation of the change in material properties due to roller bending, it imposes some drawbacks on the use of the prediction model. In most cases measured values of the yield stress prior to forming are absent and the nominal yield stress must be utilized to define the stress-strain curves with the prediction model. Using the nominal yield stress can lead to conservative assumptions of the stress-strain curves, especially for steel grade S235. The best accuracy with the prediction model is achieved when measured values for the yield stress of the straight steel are used.

\subsection{Solution procedure}

All analyses are load-controlled. As the GNIA, MNA and GMNIA are dominated by non-linear behavior the load is applied gradually in these analyses. As the primary objective is to find the ultimate load rather than post-buckling behavior the Newton-Raphson procedure was selected in preference to the arc-length method to solve the non-linear equilibrium equations. The convergence criterion for the out-of-balance load vector is equal $0.5 \%$. In addition to the force norm check a convergence criterion of $0.5 \%$ was employed for the displacement increments. For the LBA the Block-Lanczos method is used for the eigenvalue extraction.

\subsection{Load-deflection curves}

For all GMNIA the ultimate load $\alpha_{\text {ult }}$ is defined as the load level corresponding to the last converged substep. Typical load-deflection curves from GNIA and GMNIA are shown in Fig. 9 for HE 100A arches with a radially distributed load with imperfections as given in Section 2.4. The acting load $\alpha$ is normalized with respect to $\alpha_{\text {cr }}$ as found from a LBA executed on the same arch. The non-linear material model used is based on the prediction model for steel grade with $f_{\mathrm{y} ; \mathrm{s}}=235 \mathrm{~N} / \mathrm{mm}^{2}$. In order to correctly express the GMNIA results in the column curve diagram the plastic multiplier $\alpha_{\mathrm{pl}}$ must be obtained from MNA using the same non-linear material models. In addition, as 
(a) Residual stress model with element mest (b) Implementation of residual stress model in FE-code

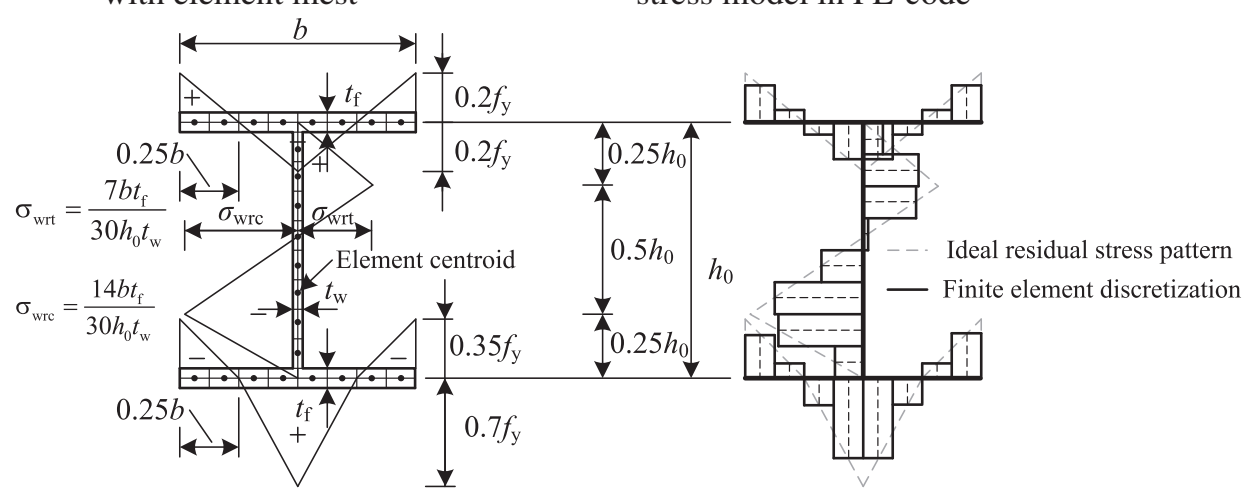

Fig. 5. Residual stress model and finite element implementation.

geometrical non-linear effects are ignored the arch continues to resist loads during the MNA as plastic straining progresses over the cross-section. In order to make a proper estimate of the plastic multiplier, the plastic collapse load is defined as the intersection between two tangents to the load-deflection curve. In Fig. 10 the loaddeflection curves are shown for MNA performed on the same arches as selected for Fig. 9, where the acting loads are normalized with respect to $\alpha_{\mathrm{cr}}$. The intersection between the two tangents defines the normalized plastic collapse load $\left(\alpha_{\mathrm{pl}} / \alpha_{\mathrm{cr}}\right)$.

\subsection{Column curve and imperfection parameter curve representation}

As mentioned in Section 2.1 each arch configuration requires 3 different analyses to be performed, allowing the ultimate load found from the GMNIA to be plotted in a column curve diagram. The column curve expression as presented in EN 1993-1-1 [19] (ECCS column curve) relates the normalized flexural buckling strength of columns $\chi$ to their non-dimensional slenderness $\bar{\lambda}$ :

$\chi=\frac{1}{\Phi \sqrt{\Phi^{2}-\bar{\lambda}^{2}}}$ but $\chi \leq 1.0$.

Where:

$\Phi=0.5\left(1+\eta+\bar{\lambda}^{2}\right)$.

The generalized imperfection or imperfection parameter is given by the following equation:

$\eta=\alpha\left(\bar{\lambda}-\bar{\lambda}_{0}\right) \geq 0$

where the factor $\alpha$ is based on the typical cross-section. Depending on the column curve used, a value for $\alpha$ is given in Table 1 . The parameter $\bar{\lambda}_{0}$ is set at 0.2 , irrespective of the column curve. For identical non-dimensional slenderness values, higher values of $\alpha$ result in an increase of $\eta$ and a decrease of $\chi$.The load amplifiers obtained from a MNA and LBA, $\alpha_{\mathrm{pl}}$ and $\alpha_{\mathrm{cr}}$, respectively, can be used to define the non-dimensional slenderness for the arch:

$\bar{\lambda}=\sqrt{\alpha_{p l} / \alpha_{c r}}$

The load amplifier $\alpha_{\text {ult }}$ can, together with $\alpha_{\mathrm{pl}}$, be used to plot the reduction factor of the arch:

$\chi=\alpha_{u l t} / \alpha_{p l}$

Eqs. (5) and(6) allow the finite element results to be plotted in a column curve diagram. Another approach to devise a design rule based on column curves is by plotting the same finite element results in an imperfection parameter diagram. When isolating the expression for $\eta$ from the column curve formulation by rewriting Eqs. (2) and (3) a different expression of $\eta$ can be obtained, which is only depending on $\chi$ and $\bar{\lambda}$ :

$\eta=\chi\left(\frac{1}{\chi^{2}}+\bar{\lambda}^{2}\right)-1-\bar{\lambda}^{2}$

Eq. (7) can be used in conjunction with Eqs. (5) and (6) to allow the finite element results to be expressed in an imperfection parameter diagram:

$\eta_{\text {num }}=\frac{\alpha_{u l t}}{\alpha_{p l}}\left(\left(\frac{\alpha_{p l}}{\alpha_{u l t}}\right)^{2}+\frac{\alpha_{p l}}{\alpha_{c r}}\right)-1-\frac{\alpha_{p l}}{\alpha_{c r}}$.

Plotting finite element results in the imperfection parameter diagram, finding an expression for the imperfection parameter and replacing Eq. (4) by the newly found expression in the column curve formulation results in an accurate expression for the column curve. Moreover, it leaves the original column curve expression intact. (a) top view

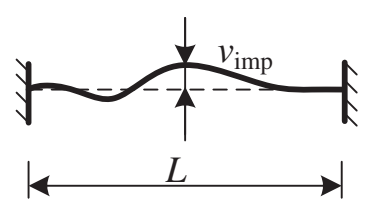

Lateral crookedness (b) elevation

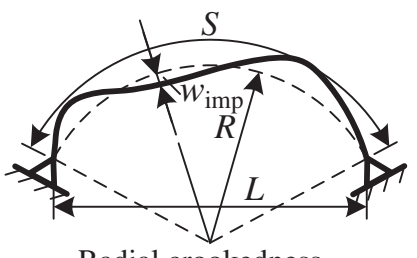

Radial crookedness (c) side view

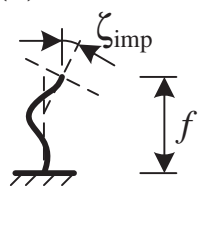

Twist imperfections

Fig. 6. Geometric imperfections measured by La Poutré. 


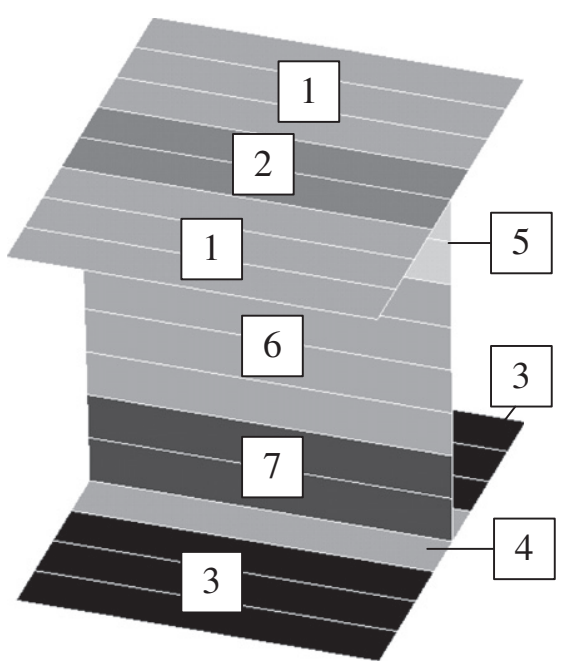

Fig. 7. Zonal distribution of mechanical properties.

The difference between plotting the finite element results in the column curve diagram using Eqs. (5) and (6) or in the imperfection parameter diagram using Eq. (8) is illustrated in Fig. 11 with the finite element data from Fig. 9 and Fig. 10 in addition to ECCS column curve "a" and " $\mathrm{d}$ ". It can be seen that plotting the finite element data in the column curve suggests that ECCS column curve "d" might be appropriate. However, looking at the imperfection parameter diagram it appears that the linear imperfection parameter expression of column curve "d" has no strong coherence with finite element results for arches with higher slenderness values. Hence, it is assumed that using the approach the imperfection parameter will result in a more accurate expression for column curves to predict the elastic-plastic buckling response of steel arches.

\subsection{Mesh refinement study}

A mesh refinement study was performed such that the finer mesh is part of the larger mesh. A HE $100 \mathrm{~A}$ with a subtended angle of $90^{\circ}$, arch length $S$ of $3 \mathrm{~m}$ and out-of-plane fixed supports with restrained warping is subjected to a radially directed uniformly distributed load. The arch is meshed with four different element distributions, where the number of elements over the flange width, web height and over the arch length is varied. For each mesh a LBA and GMNIA are performed to evaluate the normal force at the abutment at elastic buckling $\left(N_{\mathrm{cr}}\right)$ and at elastic-plastic buckling $\left(N_{\mathrm{ult}}\right)$, respectively. For the GMNIA a bi-linear material model and no residual stresses are implemented to rule out any additional discretization effects with respect to the zonal material distribution and step-wise residual stress model. The geometric imperfections for the GMNIA are based on Section 2.4.2. The results of the mesh refinement study are shown in Table 2. The difference in $N_{\text {cr }}$ and $N_{\text {ult }}$ for a specific mesh and mesh no.4 is given as well.

It can be seen that in general an increase in mesh density produces and increases in both the elastic buckling force and ultimate force. It is noted that most mesh refinement studies are characterized by a decrease in elastic buckling load and ultimate load as the mesh is further refined. The small difference between mesh no. 3 and mesh no. 4 reveals that the discretization error has almost vanished. Mesh no.3 will therefore be used for all computations. The adopted finite element mesh is shown in Fig. 3.

\section{Validation}

Experiments as published in the related paper are selected for the validation study. Full-scale tests on circular roller bent steel arches were conducted as described in a related paper by La Poutré et al. [1]. Load was applied by means of a wire hanger, which meant that it remained directed to the center of the baseline of the arch throughout the entire loading stage (this type of load is also known as a directed load). It is assumed that close coherence between the experiments by La Poutré and the finite element model for the directed load implies that the model is also able to correctly produce the out-ofplane elastic-plastic buckling response for arches under gravity loading. A full overview of the experimental plan by La Poutré is shown in Table 3. Only the experimental results from the full-scale arches were used for the evaluation of the finite element model.

The stress-strain curve obtained from coupons taken from the roller bent arches and the geometric imperfections measured prior to testing by La Poutré in addition to the residual stress model shown in Section 2.4.1 were used to define the initial state of the roller bent arch. The arch was equipped with a tension rod by means of a 3D spar element (LINK8) to represent the tension rod (directed loading). The maximum vertical displacement imposed on the tension rod during testing was also applied in the finite element model. After reaching this maximum, the imposed displacement was released, allowing the arch to deflect back. A comparison between the experimentally and numerically obtained load-deflection curves is shown in Fig. 12 for two tests. The maximum loads $\left(F_{\text {ult }}\right)$, the corresponding in-plane displacements $\left(w_{\text {ult }}\right)$, out-of-plane displacements $\left(v_{\text {ult }}\right)$ and twists ( $\zeta_{\text {ult }}$ ) as obtained from the experiments are tabulated in Table 4, and compared to finite element results. It can be seen that
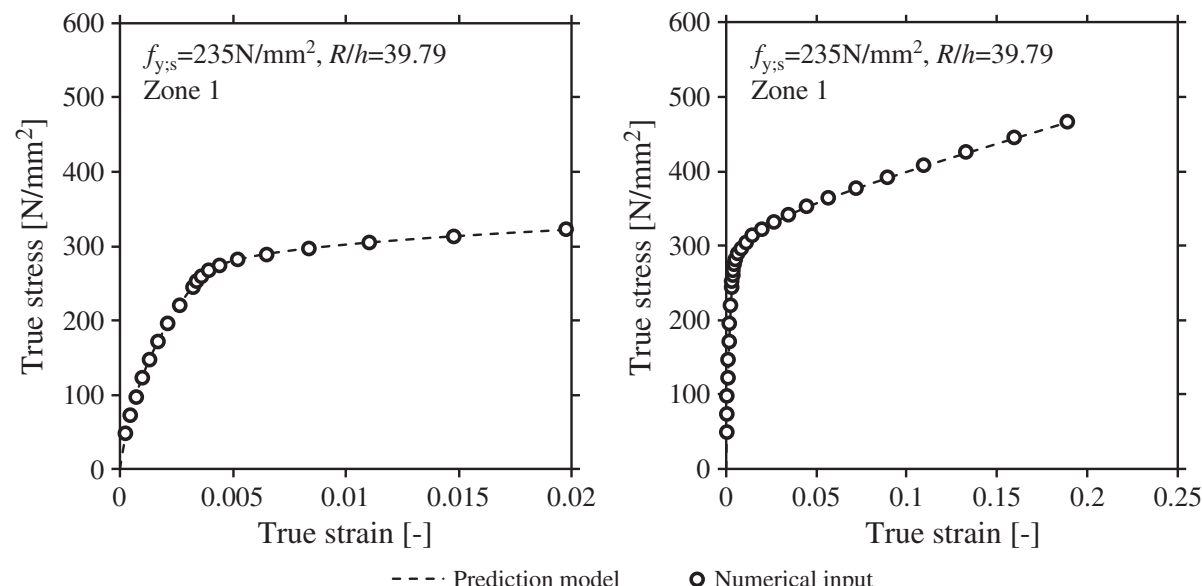

Fig. 8. Example stress-strain curves for roller bent steel, initial stage (left) full stress-strain curve (right). 

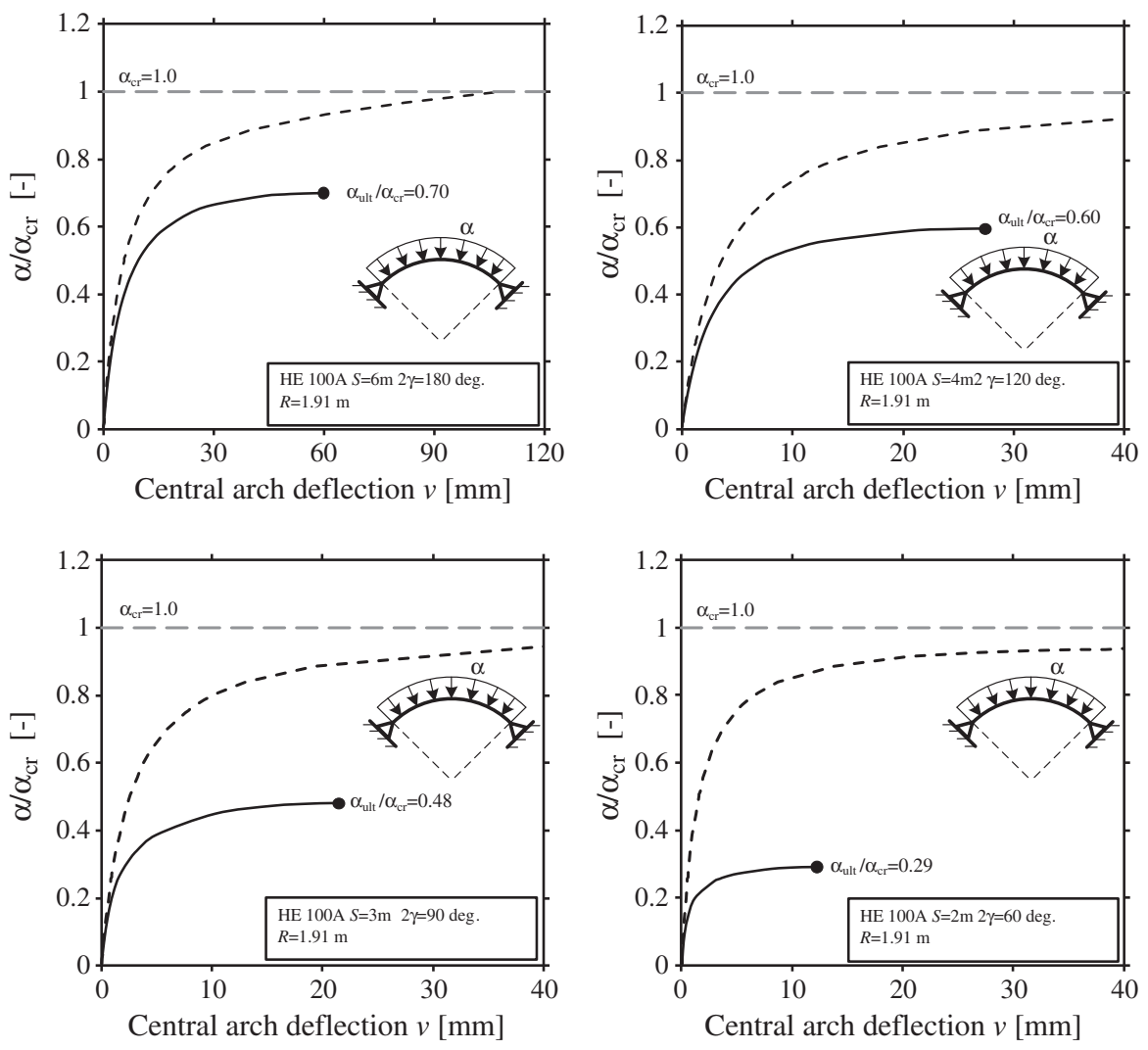

- - GNIA

- GMNIA

Fig. 9. Load-deflection curves from GNIA and GMNIA normalized with respect to the elastic buckling load from LBA
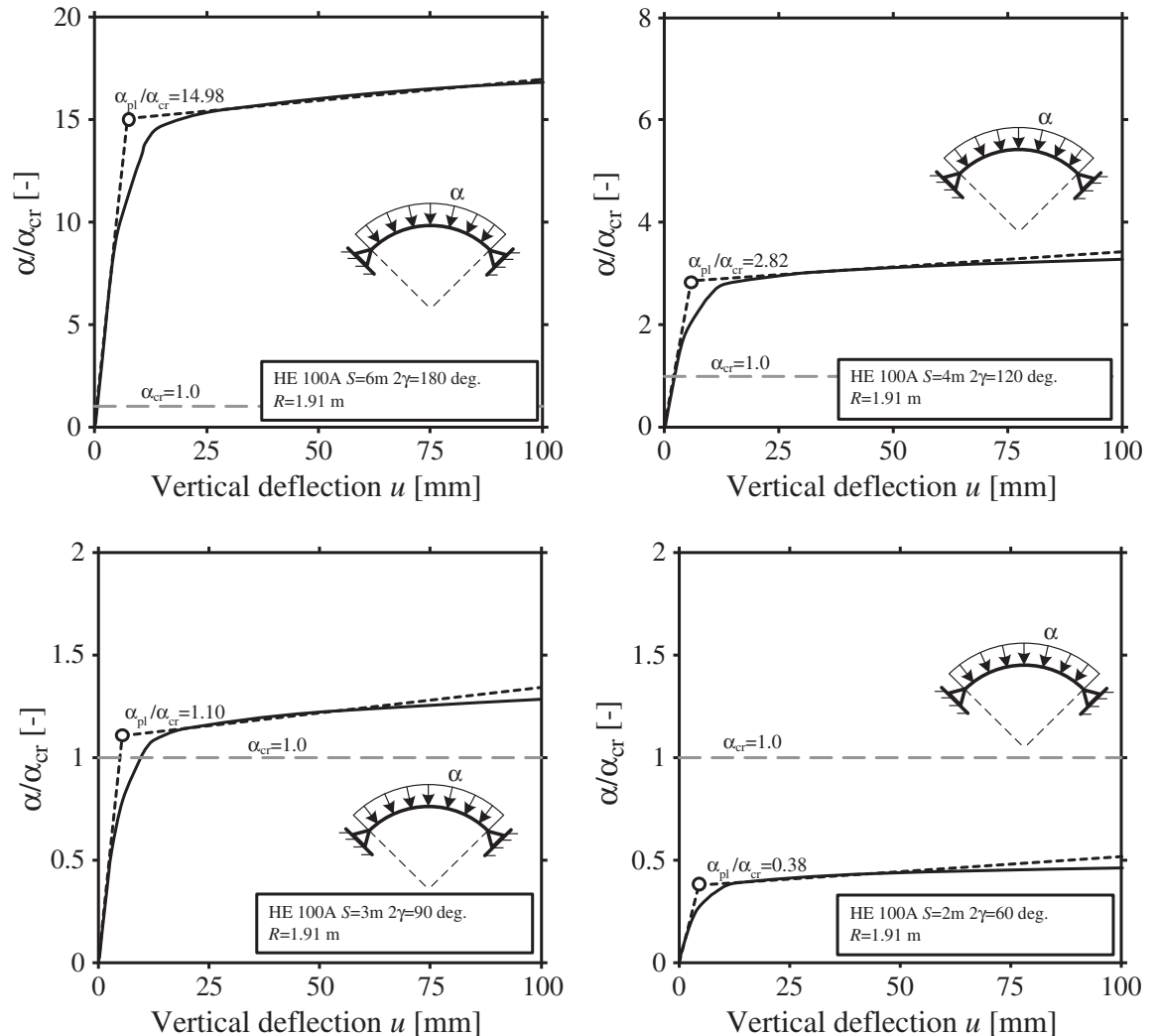

Fig. 10. Load deflection curves from MNA normalized with respect to the elastic buckling load from LBA. 
Table 1

Imperfection factor $\alpha$ for column curves according to EN 1993-1-1 [19].

\begin{tabular}{llllll}
\hline Column curve & $\mathrm{a}_{0}$ & $\mathrm{a}$ & $\mathrm{b}$ & $\mathrm{c}$ & $\mathrm{d}$ \\
\hline Imperfection value $\alpha$ & 0.13 & 0.21 & 0.34 & 0.49 & 0.76
\end{tabular}

the finite element model is able to replicate the experimental load-deflection behavior with moderate to good accuracy. Overall, the finite element model underestimates the experimentally obtained ultimate loads.

\section{Sensitivity analyses}

Sensitivity analyses were conducted on HE 100A and HE 360B arches with a radially uniformly distributed load, which resulted in uniform compression in the arch-rib. An initial residual stress distribution from Fig. 5, a geometric imperfection using the lowest global buckling mode together with an amplitude of $S / 1000$ and a bi-linear material model with nominal yield stress were used to define the baseline of the initial state of the roller bent member from which variation in imperfections was applied.

\subsection{Residual stress}

The group of arches covering a non-dimensional slenderness range of $0.6 \leq \bar{\lambda} \leq 3.8$ was used for the sensitivity analyses. For each arch a GMNIA was performed with two different residual stress models and one GMNIA was performed without inclusion of residual stresses, in addition to a GNIA. A typical hot-rolled residual stress pattern was used and the roller bending residual stress model as shown in Fig. 5. The various load deflection curves for a single arch geometry are shown in Fig. 13. The hot-rolled residual stress model is more detrimental to the elastic-plastic buckling load than the roller-bent residual stress model. The results for all arches are presented in the column curve diagram to show the sensitivity of residual stresses with respect to the arch non-dimensional slenderness. The influence of residual stresses on the elastic-plastic buckling load is most pronounced for arches with non-dimensional slenderness smaller than 1.5 .

\subsection{Geometric imperfections}

The same set of arches as employed in Section 4.1 was selected to investigate the sensitivity of a change in imperfection amplitude on the elastic-plastic buckling response. Three different levels of amplitude together with the lowest eigenmode from the LBA were used to define the out-of-straightness of the member: $S / 100, S / 1000$ and $S / 10000$. For each arch geometry with a given amplitude, two different analysis types were performed: GNIA and GMNIA. The
Table 2

Mesh refinement.

\begin{tabular}{|c|c|c|c|c|c|c|c|}
\hline \multirow[t]{2}{*}{ Mesh no. } & \multicolumn{3}{|c|}{ No. of elements } & \multicolumn{2}{|c|}{$\begin{array}{l}\text { Elastic buckling } \\
\text { force }\end{array}$} & \multicolumn{2}{|c|}{ Ultimate force } \\
\hline & $\begin{array}{l}\text { Flanges/ } \\
\text { web }\end{array}$ & Arch length & Total & $N_{\mathrm{cr}}[\mathrm{N}]$ & $\overline{\text { Diff [\%] }}$ & $N_{\text {ult }}[\mathrm{N}]$ & Diff [\%] \\
\hline 1 & 2 & 24 & 144 & 426808 & -15.28 & 317537 & -6.34 \\
\hline 2 & 4 & 48 & 576 & 488955 & -2.94 & 335417 & -1.07 \\
\hline 3 & 8 & 96 & 2304 & 501591 & -0.43 & 339160 & +0.03 \\
\hline 4 & 16 & 192 & 9216 & 503772 & - & 339049 & - \\
\hline
\end{tabular}

load-deflection curves from a single arch geometry with different amplitudes are presented in Fig. 14. A change in imperfection amplitude changes the load-deflection curves from the onset of loading and affects the buckling response to a considerable extent. The results of all GMNIA are presented in the column curve diagram. The influence of a change in amplitude is most significant within the range of $0.6 \leq \bar{\lambda} \leq 2.5$.

\subsection{Material modeling}

Arches are equipped with different material models to monitor their influence on the elastic-plastic buckling load. Each arch configuration is analyzed with different material properties: (1) nominal steel properties $\left(f_{\mathrm{y}}=235 \mathrm{~N} / \mathrm{mm}^{2}\right.$ for steel grade $\mathrm{S} 235$ and $f_{\mathrm{y}}=$ $355 \mathrm{~N} / \mathrm{mm}^{2}$ for steel grade S355) in conjunction with a bi-linear material law, resembling the material properties for straight hot-rolled steel. The second material model (2) is featured by substituting a yield stress of the material prior to forming equal to nominal values $\left(f_{\mathrm{y} ; \mathrm{s}}=f_{\mathrm{y}}\right)$ in prediction model to generate 7 different stress-strain curves for steel grade S235 and for steel grade S355. This case would resemble the situation when measured yield stresses for straight steel are absent and one has to resort to nominal values. The third material model ( 3 ) is identical as (2) but with a yield stress for the material prior to forming of $f_{\mathrm{y} ; \mathrm{s}}=290 \mathrm{~N} / \mathrm{mm}^{2}$ and $f_{\mathrm{y} ; \mathrm{s}}=$ $370 \mathrm{~N} / \mathrm{mm}^{2}$ for steel grade S235 and S355 respectively. These values give a better approximation of the measured values of the yield stress compared to nominal values in straight steel prior to forming. The results from the analyses are shown in Fig. 15.

From the comparison between the material models (2) and (3) it can be seen that the yield stress value of the material prior to roller bending is of significant influence on the results. When nominal yield stress values are substituted in the prediction model instead of yield stress values resembling measured properties from straight steel, the calculated failure load is conservative. This effect is most pronounced for steel grade S235. There exists a large difference in reduction factors $\chi$ obtained with the prediction model for steel grade
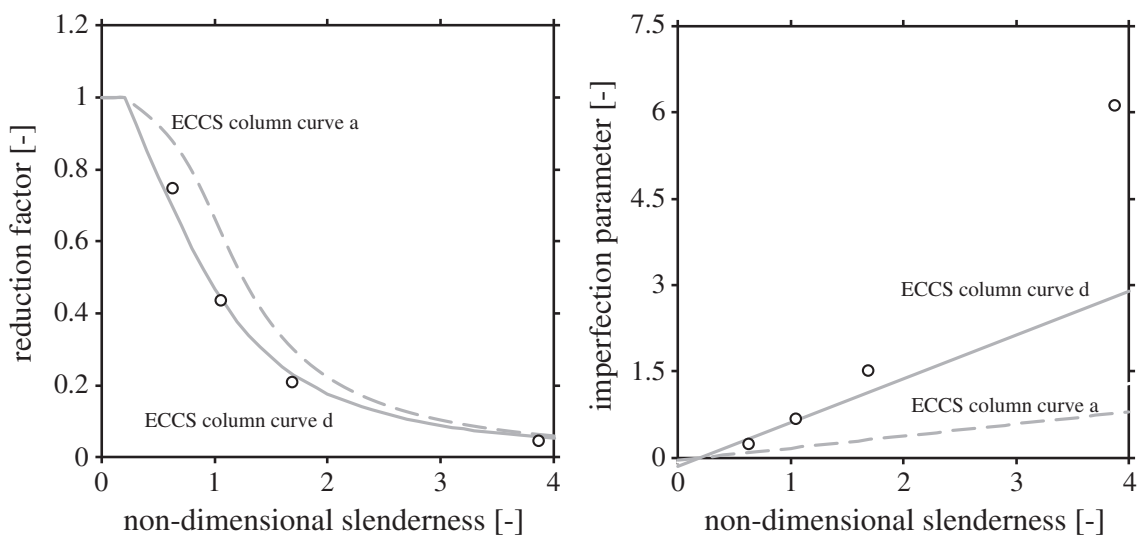

Fig. 11. Finite element results in column curve graph (left) and imperfection parameter diagram (right). 
Table 3

Experimental program La Poutré et al. [1] of full-scale arches.

\begin{tabular}{llllllll}
\hline $\begin{array}{l}\text { Test } \\
\text { no. }\end{array}$ & $\begin{array}{l}\text { No. of } \\
\text { tests }\end{array}$ & $\begin{array}{l}\text { Radius } R \\
{[\mathrm{~mm}]}\end{array}$ & $\begin{array}{l}\text { Angle } \\
2 \gamma\left[{ }^{\circ}\right]\end{array}$ & $\begin{array}{l}\text { Arch } \\
\text { length } \\
S[\mathrm{~mm}]\end{array}$ & $\begin{array}{l}\text { Rise } f \\
{[\mathrm{~mm}]}\end{array}$ & $\begin{array}{l}\text { Span } L \\
{[\mathrm{~mm}]}\end{array}$ & $\begin{array}{l}\text { Rise-to-span } \\
\text { ratio } f / L[-]\end{array}$ \\
\hline 1A, 1B, 1C & 3 & 1910 & 180 & 6000 & 1910 & 3820 & 0.50 \\
2A, 2B & 2 & 2149 & 160 & 6000 & 1775 & 4231 & 0.42 \\
3A, 3B & 2 & 2546 & 135 & 6000 & 1572 & 4705 & 0.33 \\
4A, 4B & 2 & 3125 & 110 & 6000 & 1333 & 5120 & 0.26 \\
5A, 5B, 5 C & 3 & 3820 & 90 & 6000 & 1119 & 5402 & 0.21 \\
\hline
\end{tabular}

S235 and for steel grade S355. The degree of roundness of the stressstrain curve for S235 is higher than that of S355, resulting in premature loss of stiffness and hence lower $\chi$-values.

Furthermore, it should be noted that for an incidental case a value of $\chi$ greater than 1.0 is obtained. This can be explained by the plastic multiplier $\alpha_{\mathrm{pl}}$ being determined from finite element analyses with a bi-linear material model with nominal yield stress. Arches with low non-dimensional slenderness values will have higher elastic-plastic
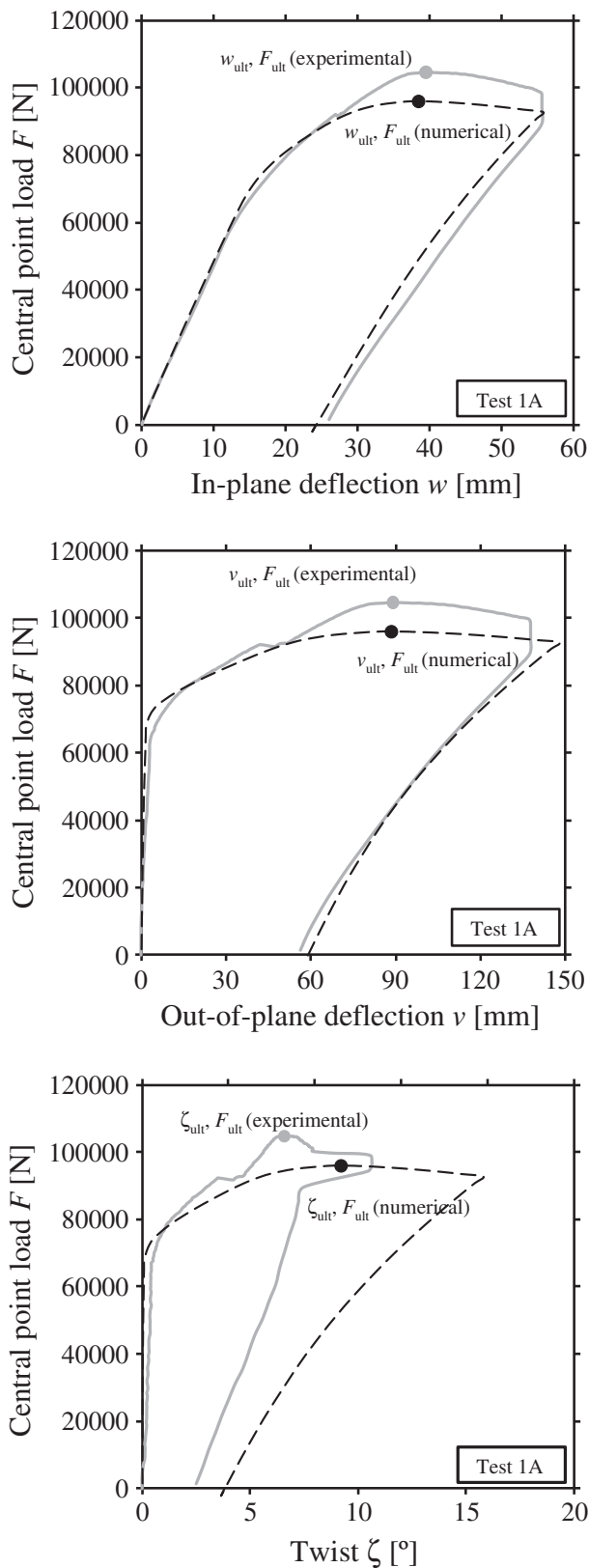

Table 4

Load-deflection results obtained from experiments and numerical analyses.

\begin{tabular}{|c|c|c|c|c|c|c|c|c|}
\hline \multirow[b]{2}{*}{$\begin{array}{l}\text { Test } \\
\text { no. }\end{array}$} & \multicolumn{4}{|c|}{ La Poutré (Exp.) } & \multicolumn{4}{|c|}{ Ratio [-] } \\
\hline & $\begin{array}{l}F_{\text {ult }} \\
{[\mathrm{kN}]}\end{array}$ & $\begin{array}{l}w_{\mathrm{ult}} \\
{[\mathrm{mm}]}\end{array}$ & $\begin{array}{l}v_{\mathrm{ult}} \\
{[\mathrm{mm}]}\end{array}$ & $\begin{array}{l}\zeta_{\text {ult }} \\
{\left[{ }^{0}\right]}\end{array}$ & $\frac{F_{\text {ult }}(\text { exp. })}{W_{\text {ult }}(\mathrm{FEM})}$ & $\frac{W_{\text {ult }}(\exp .)}{W_{\text {ult }}(\mathrm{FEM})}$ & $\frac{V_{\text {ult }}(\text { exp.) }}{V_{\text {ult }}(\mathrm{FEM})}$ & $\frac{\zeta_{\text {ult }}(\exp .)}{\zeta_{\text {ult }}(\mathrm{FEM})}$ \\
\hline $1 \mathrm{~A}$ & 104.7 & 39.5 & 89.0 & 6.59 & 1.09 & 1.03 & 1.01 & 0.72 \\
\hline 1B & 103.2 & 38.8 & 103.3 & 10.3 & 1.08 & 1.01 & 1.18 & 1.12 \\
\hline $1 \mathrm{C}$ & 104.8 & 41.6 & 93.6 & 6.35 & 1.11 & 1.08 & 1.07 & 0.70 \\
\hline $2 \mathrm{~A}$ & 104.9 & 35.0 & 65.7 & 6.10 & 1.11 & 0.91 & 0.95 & 0.79 \\
\hline $2 \mathrm{~B}$ & 104.3 & 36.1 & 69.3 & 9.22 & 1.11 & 0.96 & 1.03 & 1.24 \\
\hline $3 \mathrm{~A}$ & 100.0 & 34.7 & 68.1 & 8.21 & 1.09 & 0.96 & 1.12 & 1.07 \\
\hline 3B & 99.2 & 33.5 & 58.3 & 7.68 & 1.07 & 0.94 & 1.06 & 1.09 \\
\hline $4 \mathrm{~A}$ & 99.4 & 33.3 & 36.6 & 4.60 & 1.10 & 1.02 & 0.75 & 0.72 \\
\hline $4 \mathrm{~B}$ & 96.3 & 30.7 & 40.0 & 4.47 & 1.05 & 0.87 & 0.77 & 0.62 \\
\hline $5 \mathrm{~A}$ & 97.3 & 36.5 & 19.8 & 3.98 & 1.18 & 1.17 & 0.54 & 0.77 \\
\hline $5 B$ & 95.2 & 35.4 & 26.9 & 5.55 & 1.15 & 1.12 & 0.77 & 1.19 \\
\hline $5 \mathrm{C}$ & 95.0 & 32.0 & 41.2 & 5.00 & 1.17 & 1.02 & 1.05 & 0.89 \\
\hline
\end{tabular}
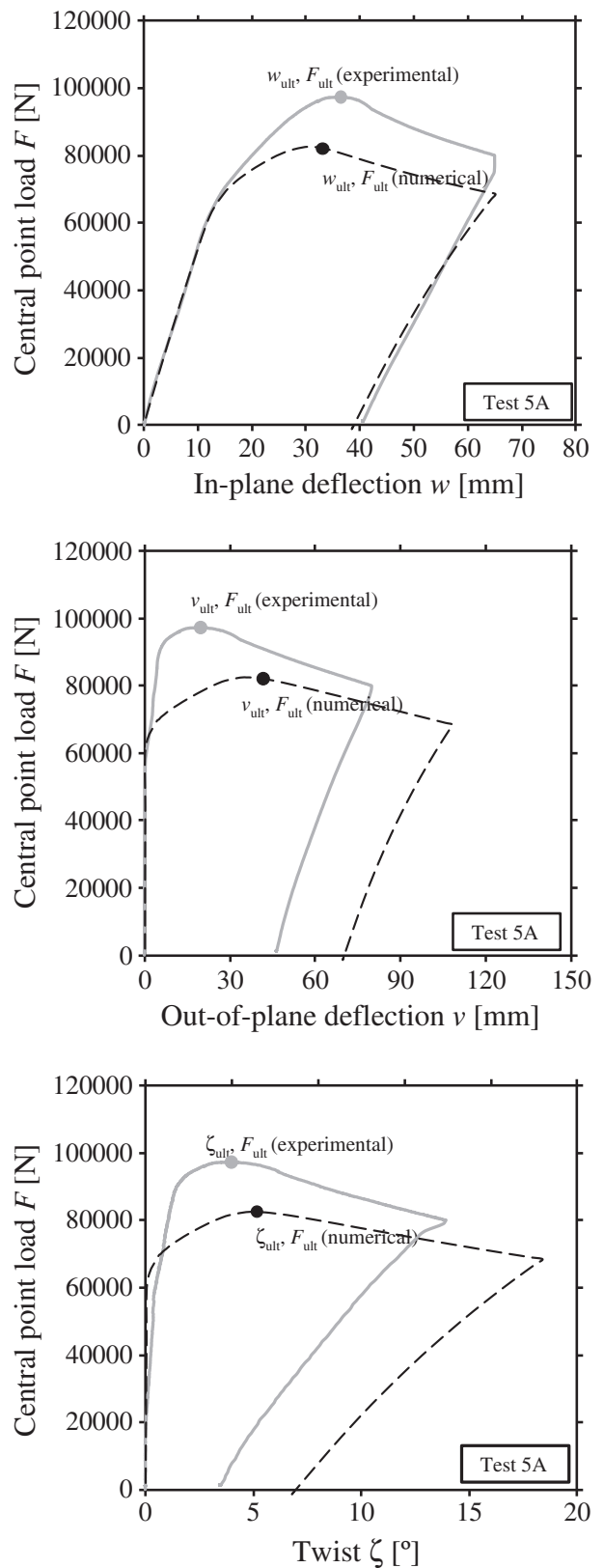

Fig. 12. Load-deflection characteristics for tests $1 \mathrm{~A}$ (left) and $5 \mathrm{~A}$ (right). 

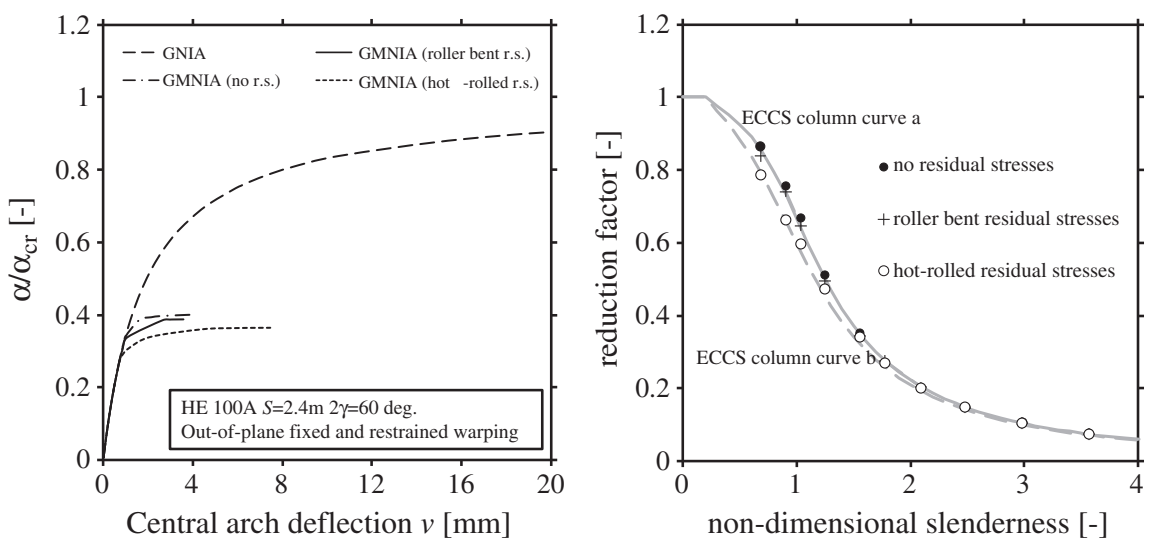

Fig. 13. Influence of residual stresses: load-lateral deflection for single HE $100 \mathrm{~A}$ (left) and results plotted in column curve diagram (right).

buckling loads than plastic collapse loads, as the former is obtained with finite element models with stress strain curves from the prediction model. For the subsequent parametric studies identical material models will be used for the MNA and GMNIA.

\section{Proposed design rule}

Based on the procedure described in Section 2.7, imperfection parameter expressions are derived to best represent the numerical data. A sample of 174 arches configurations was selected to compute the elastic-plastic buckling load, plastic collapse load and elastic buckling load, for two steel grades (S235 and S355), four load cases (Fig. 2) and two cross-sections (HE 100A and HE 360B). The non-dimensional slenderness of these arches is in the range from 0.52 to 4.75 and the subtended angle in the range from $30^{\circ}$ to $180^{\circ}$. The imperfections are based on Section 2.4. The material properties are defined by the prediction model (Section 2.4.3) with a yield stress prior to forming of $f_{\mathrm{y} ; \mathrm{s}}=235 \mathrm{~N} / \mathrm{mm}^{2}$ and $f_{\mathrm{y} ; \mathrm{s}}=355 \mathrm{~N} / \mathrm{mm}^{2}$ for steel grade S235 and steel grade S355, respectively.

In Fig. 16 the numerical results are shown in the imperfection parameter diagram for arches under uniform bending or uniform compression and steel grade S235 or S355 for $0 \leq \bar{\lambda} \leq 4.0$ and $0 \leq \eta \leq 2.0$. The imperfection parameter expression of ECCS column curve "a" and " $\mathrm{d}$ " is shown in addition to the calibrated imperfection parameter expression, denoted with the dashed gray lines and solid black line, respectively. The calibrated imperfection parameter expression is obtained with linear regression analyses. It can be clearly seen that for these arches, the imperfection parameter increases linearly with non-dimensional slenderness. Hence linear imperfection parameter expressions were selected in preference to higher order expressions for the regression analyses. The steepness of the calibrated curves is different for arches under uniform bending or uniform compression and also depends on the steel grade.

Finite element results for arches with a central point load or a uniformly distributed load and for steel grade S235 or steel grade S355 are shown in Fig. 17 for $0 \leq \bar{\lambda} \leq 4.0$ and $0 \leq \eta \leq 1.5$. With the exception of an arch subjected to a central point load and steel grade S355, all imperfection parameters show a linear increase with non-dimensional slenderness. Hence a linear expression selected for these arches to arrive at an imperfection parameter expression. When looking at the imperfection parameter diagram for arches with steel grade S355, subjected to a central point load, it can be seen that for low slenderness values the imperfection parameter is fairly constant at $0.3<\eta<0.5$ However, for higher non-dimensional slenderness values the imperfection parameter drops suddenly. For these arches a polynomial of the 2nd order was selected to arrive at a closed-form expression of the imperfection parameter.

The description of the imperfection parameters are given in Table 5. For each load case and steel grade an imperfection parameter expression is presented. These expressions can be substituted into Eq. (3) to obtain the column curve formulation for roller bent arches subject to out-of-plane elastic plastic buckling failure.

\section{Discussion}

Using the design rule requires the availability of two intrinsic arch properties: the elastic buckling load and the in-plane plastic capacity to compute the arch non-dimensional slenderness $\bar{\lambda}$ and the reduction factor $\chi$. In the parametric studies, the elastic buckling load and in-plane plastic capacity were determined with the same finite
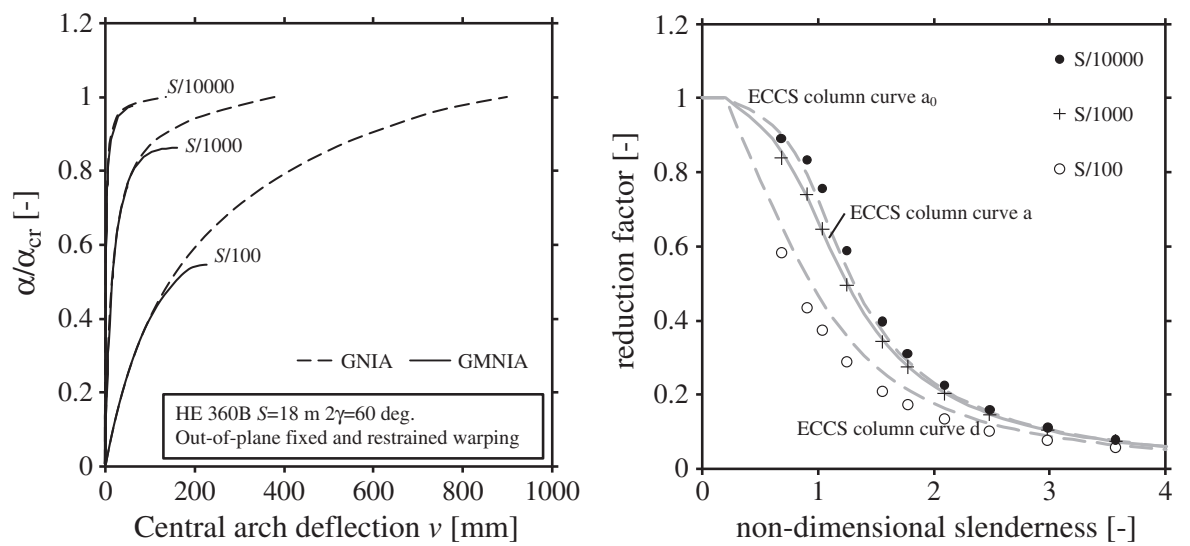

Fig. 14. Influence of amplitude: load-lateral deflection for single HE $100 \mathrm{~A}$ (left) and results collated in column curve diagram (right). 

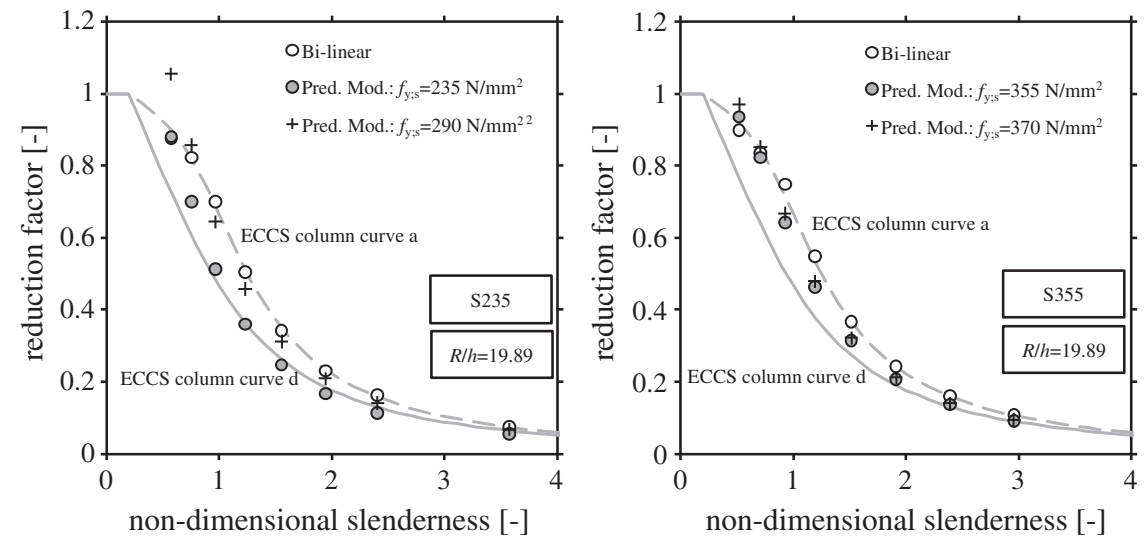

Fig. 15. Influence of material models: Steel grade S235 (left) and steel grade S355 (right).

element model as from which the ultimate load was obtained. This hampers the feasibility of the design rule as it obliges the engineer to make finite element calculations to compute both $\alpha_{\mathrm{cr}}$ and $\alpha_{\mathrm{pl}}$ to check the out-of-plane buckling response.

Design graphs to approximate the in-plane plastic collapse load for arches subjected to a single force applied at the crown and a uniformly distributed load are given in Spoorenberg et al. [24]. In order to obtain the elastic buckling load research contributions by Namita [25], Usami and Koh [26] for arches under a uniformly distributed load and Pi et al. [27] for an arch under a central point load can be used.

\section{Conclusions}

A design rule was proposed based on finite element analyses, to check the out-of-plane buckling response of freestanding circular roller bent steel arches under symmetric loads. Earlier published models for the residual stresses and mechanical properties typical for roller bent steel were used to define the initial state of the finite element model prior to loading. Sensitivity analyses were performed, to investigate the influence of imperfections on the out-of-plane elastic plastic buckling response, from which the following conclusions can be drawn.

- Residual stresses in roller bent steel are less detrimental to elasticplastic buckling of steel arches when compared to residual stress patterns in hot-rolled steel.

- The results from finite element models with gradual yielding typical for roller bent steel show a significant decrease in elastic-plastic buckling load in comparison to finite element computations performed on arches with bi-linear material models resembling hot-rolled steels.
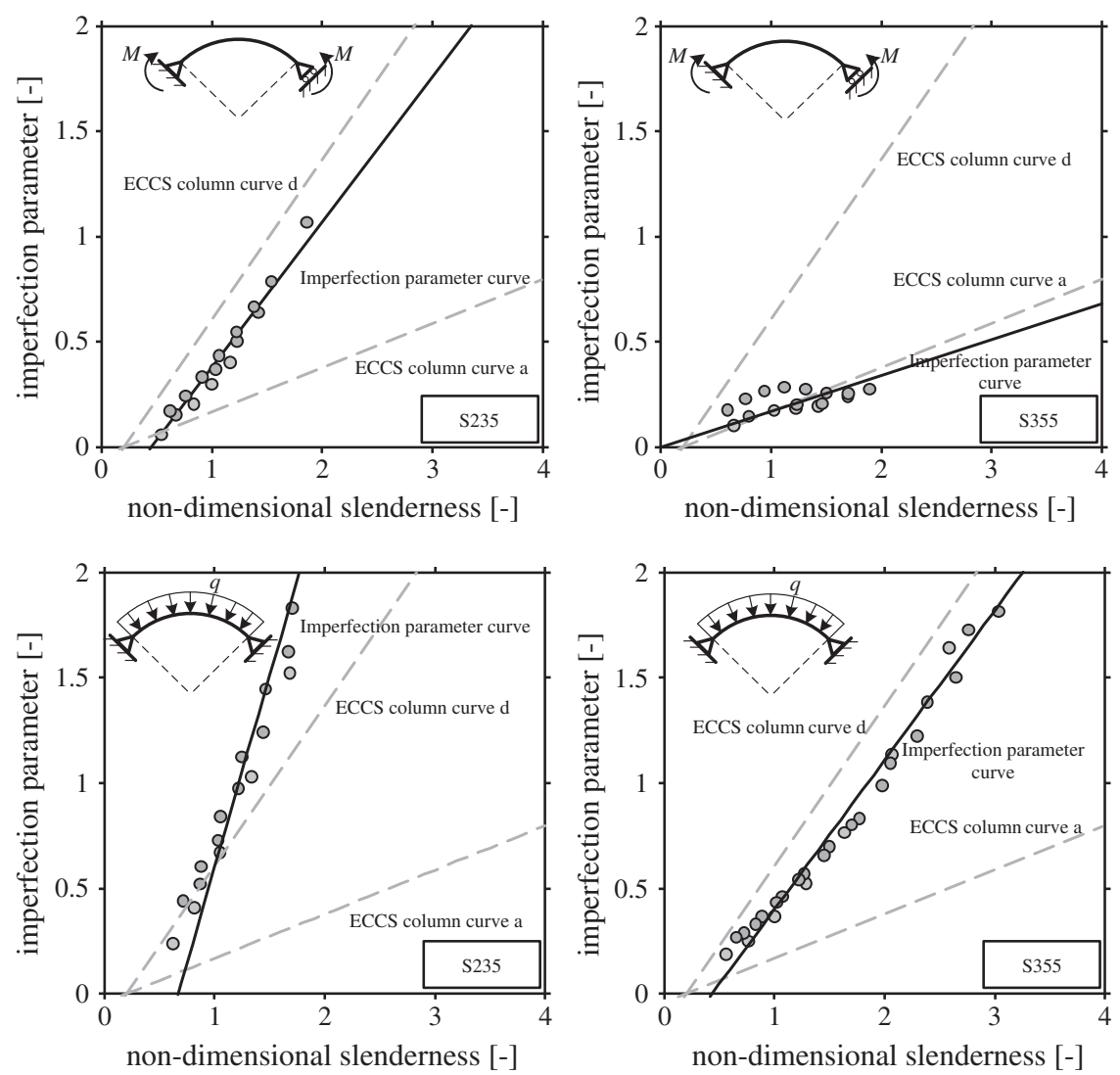

Fig. 16. Imperfection parameter diagram for arches under uniform bending and uniform compression for steel grade S235 and steel grade S355. 

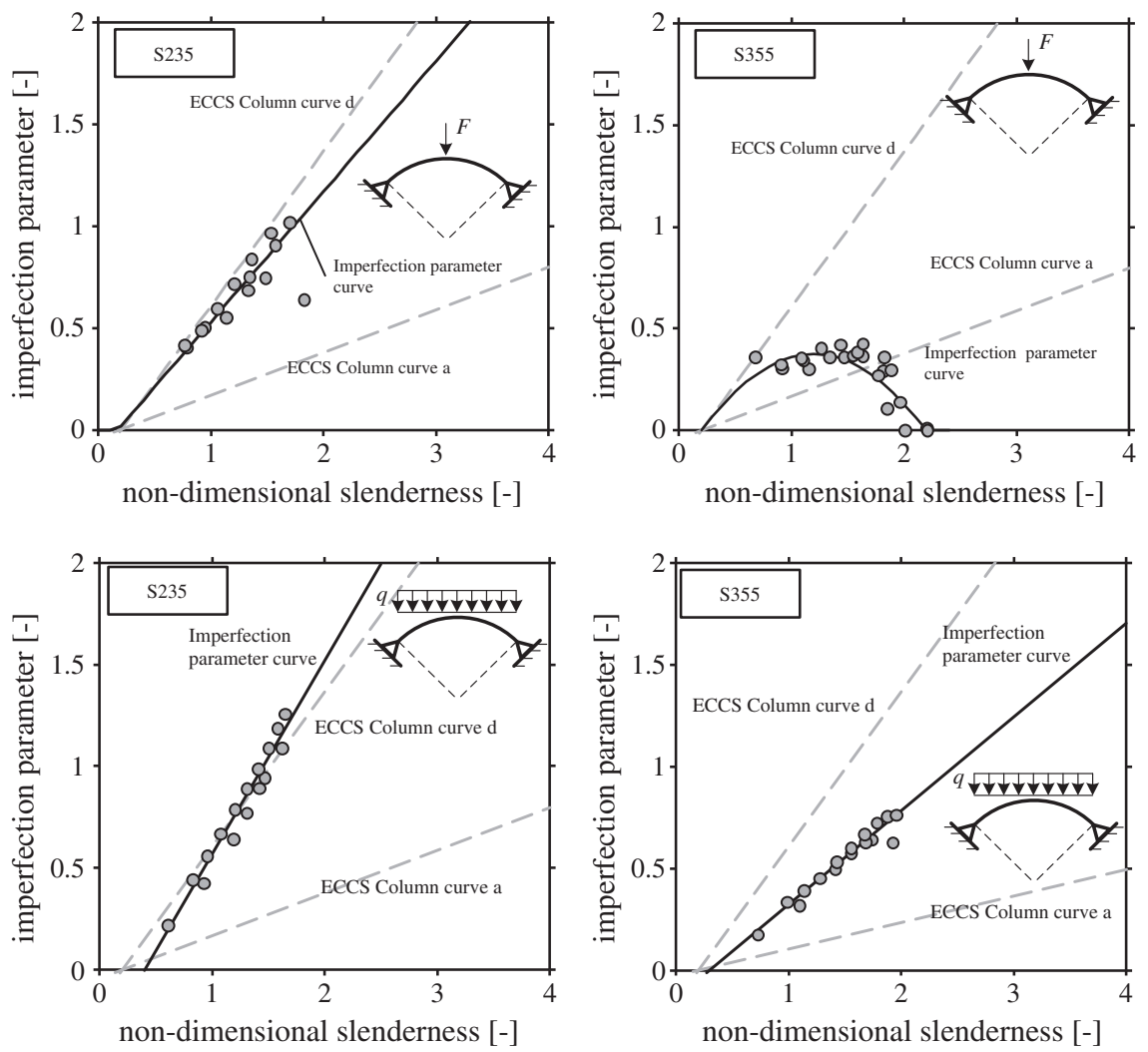

Fig. 17. Imperfection parameter diagram for arches with a central point load and a uniformly distributed load for steel grade S235 and steel grade S355.

From the numerical analyses, a large database was created containing the elastic-plastic buckling response for a wide range of arch configurations. The solution was plotted in generalized imperfection parameter diagrams and generalized imperfection parameter expressions were derived through curve fitting techniques. The imperfection expressions can be substituted into the column curve formulation to render the European column curve applicable for roller bent arches, leaving the original column curve formulation unaltered. It was found that the imperfection curve is highly dependent on the steel grade and load case which resulted in a total of eight different imperfection parameter expressions and hence eight different column curves to predict the buckling response of roller bent arches for four different load cases with two different steel grades. Provided the arch slenderness is known, the design rule can be a useful tool to check the out-of-plane buckling response of freestanding roller bent steel arches.

\section{Acknowledgements}

This paper is based on the Ph.D. thesis of the first author. In addition to the co-authors, the following members of the Ph.D. committee contributed to the completion of the thesis and (indirectly) to this paper: Prof. Soetens (Eindhoven University of Technology), Prof. Sluys (Delft University of Technology), Prof. van Bogaert (Gent

Table 5

Imperfection parameter $\eta$.

\begin{tabular}{lll}
\hline Load case & Steel grade S235 & Steel grade S355 \\
\hline Central load & $0.63 \bar{\lambda}-0.11$ & $-0.30 \bar{\lambda}^{2}+0.90 \bar{\lambda}-0.17$ \\
Uniformly distributed load & $0.95 \bar{\lambda}-0.38$ & $0.46 \bar{\lambda}-0.14$ \\
Uniform bending & $0.69 \bar{\lambda}-0.31$ & $0.17 \bar{\lambda}$ \\
Uniform compression & $1.82 \bar{\lambda}-1.22$ & $0.71 \bar{\lambda}-0.31$ \\
\hline
\end{tabular}

University) and Dr. Maljaars (TNO). The authors would like to acknowledge their input and valuable comments.

\section{References}

[1] La Poutré DB, Spoorenberg RC, Snijder HH, and Hoenderkamp JCD. Experimental investigation of the out-of-plane stability of roller bent steel arches. Journal of Constructional Steel Research submitted for publication.

[2] Timoshenko SP, Gere JM. Theory of elastic stability. Tokyo: McGraw-Hill; 1961.

[3] Vlasov VZ. Thin-walled elastic beams. Jerusalem: Israel Program for Scienftic Translations Ltd; 1961.

[4] Vacharajittiphan P, Trahair NS. Flexural-torsional buckling of curved members. J Struct Div 1975;101(6):1223-38.

[5] Yoo CH. Flexural-torsional stability of curved beams. J Eng Mech Div 1982;108(6): 1351-69.

[6] Rajasekaran S, Padmanabhan S. Equations of curved beams. J Eng Mech ASCE 1989;115(5):1094-111.

[7] Sakimoto T, Yamao T, Komatsu S. Experimental study on the ultimate strength of steel arches. Proc Japan Soc Civ Eng 1979;286:139-49.

[8] Sakata T, Sakimoto T. Experimental study on the out-of-plane buckling strength of steel arches with open cross-section. Proc Japan Soc Civ Eng 1990;416:101-12.

[9] Komatsu S, Sakimoto T. Ultimate load carrying capacity of steel arches. J Struct Div 1977;103(12):2323-36.

[10] Sakimoto T, Komatsu S. Ultimate strength formula for central-arch-girder bridges Proc Japan Soc Civ Eng 1983;333:183-6.

[11] Sakimoto T, Komatsu S. Ultimate strength formula for steel arches. J Struct Eng ASCE 1983;109:613-27.

[12] Sakimoto T, Sakata T, Tsuruta E. Elasto-plastic out-of-plane buckling strength of through type and half-through type arch bridges. Proc Japan Soc Civ Eng 1989;410:137-48.

[13] Sakimoto T, Sakata T. The out-of-plane buckling strength of through-type arch bridges. J Constr Steel Res 1990;16:307-18.

[14] Papangelis JP, Trahair NS. Flexural-torsional buckling tests on arches. J Struct Eng ASCE 1987;113(7):1433-43.

[15] Pi Y-L, Trahair NS. Nonlinear inelastic analysis of steel beam-columns. I: theory. J Struct Eng ASCE 1994;121(9):2041-61.

[16] Pi Y-L, Trahair NS. Out-of-plane inelastic buckling and strength of steel arches J Struct Eng ASCE 1998;124(2):174-83.

[17] Pi Y-L, Bradford MA. Out-of-plane strength design of fixed steel I-section arches. J Struct Eng ASCE 2005;131(4):560-8.

[18] Pi Y-L, Trahair NS. Inelastic lateral buckling strength and design of steel arches. Eng Struct 2000;22(8):993-1005. 
[19] EN 1993-1-1. Eurocode 3. Design of steel structures, general rules and rules for buildings. Brussels: CEN European Committee for Standardization; 2004.

[20] Spoorenberg RC, Snijder HH, Hoenderkamp JCD. Proposed residual stress model for roller bent wide flange steel sections. J Constr Steel Res 2011;67(6):992-1000.

[21] La Poutré DB. Inelastic spatial stability of circular wide flange steel arches. Ph.D. thesis. Eindhoven: Eindhoven University of Technology; 2004.

[22] Spoorenberg RC. Structural properties and out-of-plane stability of roller bent steel arches. Ph.D. thesis. Eindhoven: Eindhoven University of Technology: 2011.

[23] Spoorenberg RC, Snijder HH, Hoenderkamp JCD. Mechanical properties of roller bent wide flange sections - part 2: prediction model. J Constr Steel Res 2012;68(1): 63-77.
[24] Spoorenberg RC, Snijder HH, Hoenderkamp JCD. A theoretical method for calculating the collapse load of steel circular arches. Eng Struct 2012;38:89-103.

[25] Namita Y. Die Theorie II. Ordnung von krummen Stablen und ihre Anwendung auf das Kipp-Problem des Bogentragers. Trans Japan Soc Civ Eng 1968;155:32-41.

[26] Usami T, Koh SY. Large displacement theory of thin-walled curved members and its application to lateral-torsional buckling analysis of circular arches. Int J Solids Struct 1980;16:71-95.

[27] Pi Y-L, Bradford MA, Tong G-S. Elastic lateral-torsional buckling of circular arches subjected to a central concentrated load. Int J Mech Sci 2010;52(6):847-62. 